\title{
Aplicação da técnica de PCR na detecção de Yersinia enterocolitica em suínos abatidos sem inspeção
}

[PCR technique application in Yersinia enterocolitica detection in non-inspected swine]

\author{
V.A.M. Teodoro ${ }^{1}$, P.S.A. Pinto ${ }^{1}{ }^{*}$, M.C.D. Vanetti ${ }^{1}$, P.D. Bevilacqua ${ }^{1}$, M.P. Moraes ${ }^{1}$, M.S. Pinto ${ }^{2}$ \\ ${ }^{1}$ Departamento de Veterinária - UFV \\ Av. P.H. Rolfs, s/n \\ 36570-000 - Viçosa, MG \\ ${ }^{2}$ Bolsista de Iniciação Científica
}

\begin{abstract}
RESUMO
Avaliou-se a contaminação de carcaças e tonsilas de suínos por Y. enterocolitica em estabelecimentos de abate não inspecionados, comparando a pesquisa microbiológica convencional com a técnica da reação em cadeia de polimerase (PCR) e o tipo de amostra analisada (de tonsila ou de carcaça), como subsídio ao monitoramento microbiano em sistemas de análise de perigos e pontos críticos de controle. Calcularam-se os custos dos dois testes. Não se detectou $Y$. enterocolitica pela técnica microbiológica convencional, mas, pela técnica de PCR foi possível detectar a bactéria em $40 \%$ das carcaças e em $43 \%$ das tonsilas, incluindo cepas patogênicas nas tonsilas. Não houve diferença entre os resultados positivos para as amostras de tonsilas e esfregaços de superfície das carcaças. A PCR apresentou-se como uma alternativa na detecção do agente e uma técnica aparentemente mais eficaz, econômica e rápida. Os resultados indicam a PCR como um importante recurso para o controle de qualidade da carne suína.
\end{abstract}

Palavras-chave: suíno, contaminação, Yersinia enterocolitica, PCR, APPCC

\begin{abstract}
The contamination of swine carcasses and tonsils by Yersinia enterocolitica in slaughterhouses without inspection was evaluated. The conventional microbiological analysis was compared with the PCR technique of carcass or tonsil swabs, as a subsidy to the microbiological evaluation in the HACCP system. The costs of the two techniques were also calculated. Y. enterocolitica was not detected by the conventional microbiological analysis. Using the PCR, it was possible to detect this bacterium in carcass (40\%) and tonsil (43\%) samples. There was no difference between the positive results for the carcass and tonsil samples. The PCR showed to be a more effective, fast and economic alternative for the Y. enterocolitica detection, as compared to the conventional microbiological analysis.
\end{abstract}

Keywords: swine, contamination, Yersinia enterocolitica, PCR, HACCP

Recebido em 12 de maio de 2004

Aceito em 5 de agosto de 2005

*Autor para correspondência (corresponding author)

E-mail: pintopsa@ufv.br 


\section{INTRODUÇ̃̃̃O}

A yersiniose é uma doença humana causada pela Yersinia enterocolitica, que se caracteriza por sintomas gastroentéricos variáveis de acordo com a pessoa infectada, associando-se geralmente à enterocolite ou linfadenite mesentérica. Pode também estar acompanhada de outras complicações sépticas em crianças, idosos e pessoas debilitadas ou imunocomprometidas (Germano e Germano, 2003).

Nos últimos anos, houve um aumento considerável da incidência dessa enterobactéria nos seres humanos e em alimentos. No Brasil, $Y$. enterocolitica foi isolada do ser humano, de cães e suínos, enfermos e sadios, da água e de alimentos, como carne e derivados, leite e vegetais, principalmente nos estados de São Paulo, Rio de Janeiro e Rio Grande do Sul.

Segundo Asplund et al. (1990) e De Boer e Nouws (1991), existe estreita associação entre incidência da infecção com o consumo de alimentos contaminados, especialmente da carne suína.

O isolamento de $Y$. enterocolitica de fezes, língua, tonsilas ou carne de suínos tem sido relatado em diversos países, como Japão (Fukushima et al., 1997), Canadá, Dinamarca e Nova Zelândia (Rajic, 2000), Estados Unidos, Bélgica e Suécia (Neubauer et al., 2000).

Alguns sorotipos patogênicos para o ser humano têm sido isolados com freqüência em suínos, sugerindo serem eles importante reservatório da enterobactéria (Nesbakken, 1988; Asplund et al., 1990). Marcadores de patogenicidade já foram identificados no genoma dessa bactéria. Seqüências homólogas do gene ail foram encontradas exclusivamente em cepas patogênicas, ao passo que seqüências homólogas do inv apresentavam-se em todas as cepas (Aarts et al., 2001; Wannet et al., 2001). Tem-se ainda utilizada a amplificação de seqüências específicas do gene ail para a identificação de $Y$. enterocolitica patogênica por reação em cadeia de polimerase (PCR) (Leal et al., 1997; Wannet et al., 2001).

Atualmente, como recurso adicional à análise microbiológica convencional, testes de PCR têm sido padronizados para a detecção de $Y$. enterocolitica. Segundo Aarts et al. (2001), na maioria dos casos, esses testes se baseiam em genes de patogenicidade localizados no cromossomo bacteriano, o yst ou o ail.

Vários meios de cultura têm sido desenvolvidos para o isolamento e a identificação de Yersinia enterocolitica. O ágar cefsulodina-irgasannovobiocina (CIN), desenvolvido por Schiemann, em 1979, inibe o crescimento da maioria das outras bactérias, sendo uma boa opção para $\mathrm{o}$ isolamento seletivo da $Y$. enterocolitica de praticamente qualquer tipo de amostra (Sulakveilidze, 2000).

Ao avaliarem as técnicas de isolamento e enriquecimento que têm sido propostas para $Y$. enterocolitica em gêneros alimentícios, Walker e Gilmour (1986) observaram que o préenriquecimento em caldo tripticase de soja (TSB), seguido pelo enriquecimento seletivo em meio bile-oxalato-sorbose (BOS) e pelo plaqueamento em ágar CIN propiciou crescimento considerável de Yersinia $s p$ e inibiu satisfatoriamente a microbiota competidora. Meios alcalinos também têm sido recomendados para isolar Yersinia, porque inibem grande número de contaminantes. A capacidade da $Y$. enterocolitica de crescer a $4^{\circ} \mathrm{C}$ também pode ser utilizada para selecioná-la, porém esse tipo de enriquecimento requer longo período de incubação, tornando-o inviável para o controle de qualidade alimentar.

O sistema de análise de perigos e pontos críticos de controle (APPCC) baseia-se na identificação, avaliação e controle dos perigos advindos do processo de abate e do processamento dos alimentos nas linhas de produção, distribuição e consumo, empregando ações preventivas ou corretivas. Para garantir a exeqüibilidade desse sistema, o monitoramento e a verificação na linha de abate devem ser desenvolvidos rotineiramente com técnicas adequadas, nos pontos críticos de controle (PCC) dessa linha (Organização..., 2001).

Este trabalho teve o objetivo de avaliar a contaminação de carcaças e tonsilas suínas por $Y$. enterocolitica em ambientes de abate, comparando a pesquisa microbiológica convencional com a técnica de PCR e o tipo de amostra analisada, como subsídio ao sistema APPCC. 


\section{MATERIAL E MÉTODOS}

Amostras coletadas em três estabelecimentos de abate sem inspeção, constituídas, aleatoriamente, de 30 esfregaços (suabes) de carcaça e 30 tonsilas de suínos, foram analisadas por meio de pesquisa microbiológica convencional e pela técnica de PCR, visando à detecção de $Y$. enterocolitica.

A pesquisa microbiológica convencional de Yersinia $s p$ foi realizada segundo técnica descrita por Silva et al. (1997), adaptada por Johannessen et al. (2000). Foram seguidas as etapas de: enriquecimento primário em caldo tripticase de soja e em caldo Rappaport modificado, enriquecimento secundário em solução salina fosfatada tamponada seguido de tratamento com $\mathrm{KOH}$ a $0,5 \%$ e plaqueamento em ágar MacConkey, ágar Salmonella-Shigella desoxicolato e ágar cefsulodina irgasan novobiocina, e identificação bioquímica pelas provas de crescimento em ágar Kligler ferro, de hidrólise da uréia, de utilização do citrato e de fermentação de sacarose, L-ramnose, D-rafinose, D-melibiose e $\alpha .-$ metil-D-glicosídeo.

Para a reação da PCR, foram utilizados os homogenatos obtidos por centrifugação, partindo de suabes e de fragmentos das tonsilas. As amostras de DNA foram obtidas pelo método de extração fenol:clorofórmio, realizado segundo metodologia padrão descrita por Sambrook et al. (1989).

Após a extração do DNA, foi realizada a PCR, específica para identificação da espécie $Y$. enterocolitica. Somente das amostras positivas foi feita a reação de PCR para reconhecimento das cepas patogênicas. Utilizou-se uma cultura de Y. enterocolitica ATCC 9610 como controle positivo para todas as reações. Esse controle positivo foi testado pelo método microbiológico convencional, com perfil bioquímico característico, para visualização do tamanho correto da banda. O controle negativo utilizado constituiu-se em cultura de Listeria monocytogenes. Ambos os controles foram fornecidos pela Fundação Oswaldo Cruz.

As técnicas da PCR foram realizadas segundo Wannet et al. (2001) e Uyeda et al. (2003). Juntamente com o marcador molecular Sigma øX174, foram utilizados na amplificação do
DNA dois pares de oligonucleotídeos: $16 \operatorname{SrRNA}$ I (5'-AAT ACC GCA TAA CGT CTT CG-3') e 16SrRNA II (5'-CTT CTT CTG CGA GTA ACG TC-3'), com $330 \mathrm{pb}$, específicos da espécie $Y$. enterocolitica e ail I (5'-TTA ATG TGT ACG CTG GGA GTG-3') e ail II (5'-GGA GTA TTC ATA TGA AGC GTC-3'), com 425 pb, indicadores de cepas patogênicas de $Y$. enterocolitica.

Realizou-se a análise de custos das provas microbiológica convencional e PCR quanto às despesas com material de consumo, não sendo consideradas as despesas com mão-de-obra, vidrarias, equipamentos e encargos sociais, entre outros.

\section{RESULTADOS E DISCUSSÃO}

Não foi detectada $Y$. enterocolitica pela técnica microbiológica convencional, mas o foi pela técnica de PCR, em amostras de carcaças (40\%) e de tonsilas (43\%). A PCR também permitiu determinar a presença de cepas patogênicas nas tonsilas positivas para $Y$. enterocolitica (Tab. 1).

Tabela 1. Freqüência de $Y$. enterocolitica e $Y$. enterocolitica patogênica por carcaça, tonsilas suínas e suínos analisados pela técnica da PCR

\begin{tabular}{lcc}
\hline & Y. enterocolitica & $\begin{array}{c}Y . \text { enterocolitica } \\
\text { patogênica }\end{array}$ \\
\hline Carcaça & $12 / 30(40 \%)$ & $00 / 30(0 \%)$ \\
Tonsila & $13 / 30(43 \%)$ & $03 / 30(10 \%)$ \\
Suínos & $22 / 30(73 \%)$ & $03 / 30(10 \%)$ \\
\hline
\end{tabular}

$\mathrm{O}$ resultado negativo à análise microbiológica convencional pode ser explicado pelo fato de a $Y$. enterocolitica ser pouco competitiva na presença de outros microrganismos, crescer mais lentamente e ser rapidamente inibida, além de ser encontrada em pequeno número nos alimentos, concorrendo com grande variedade da microbiota competidora (Doyle e Hugdahl, 1983). Ressalta-se, ainda, que pode ter ocorrido interferência metodológica, pois, embora tenha sido utilizado, no plaqueamento, um meio de cultura seletivo mais indicado para o isolamento de colônias, o ágar CIN (Walker e Gilmour, 1986; Sulakveilidze, 2000), o meio de enriquecimento secundário preferido por vários pesquisadores (Schiemann, 1982; Walker e Gilmour, 1986), o Caldo BOS, não foi utilizado. 
O método microbiológico convencional mostrouse menos sensível que a PCR, o que também foi relatado por Johannessen et al. (2000), em experimento com produtos derivados da carne suína. Pela técnica convencional, $Y$. enterocolitica O:3 foi isolada de seis amostras (2\%), enquanto a PCR indicou a presença da $Y$. enterocolitica patogênica em 50 amostras (17\%). Neste estudo, realçou-se a necessidade de se aprimorar a técnica microbiológica convencional aplicada na detecção da $Y$. enterocolitica em alimentos.

A pesquisa microbiológica convencional de $Y$. enterocolitica demanda um período de até 20 dias para a confirmação da espécie, e, para a identificação da cepa, são necessárias provas adicionais de biotipagem e sorotipagem, absorvendo mais tempo, enquanto que a técnica da PCR pode ser realizada em 24 horas. Segundo Wannet et al. (2001), a análise pela PCR reduz significativamente o tempo necessário para identificar a $Y$. enterocolitica patogênica e não patogênica. Diante de um surto de infecção alimentar, a pesquisa convencional torna-se demorada e menos oportuna, não devendo, entretanto, ser descartada como prova complementar.

Quanto ao custo do material de consumo (meios de cultura e reagentes), a PCR foi mais econômica. Para cada amostra analisada pela PCR, gasta-se em torno de U\$1,50, e pela análise convencional, U\$ 9,21. Ressalta-se, no entanto, que a análise de custos se referiu apenas a material de consumo, não sendo consideradas, nos cálculos, as despesas com equipamentos, vidrarias, mão-de-obra, entre outros.

Nesbakken et al. (2003) compararam o método microbiológico convencional, a PCR e o ELISA e não encontraram diferença significativa quanto à eficácia deles. Apesar disso, esses autores consideraram a PCR e o ELISA melhores alternativas do que a análise microbiológica convencional na avaliação e verificação do sistema APPCC em matadouros, por se constituírem métodos mais rápidos $\mathrm{e}$ econômicos.

Wannet et al. (2001) também consideraram a técnica de PCR uma ferramenta mais útil que a análise microbiológica convencional para a detecção de $Y$. enterocolitica, por ser mais rápida, sensível e específica. Porém, a detecção de $Y$. enterocolitica pela PCR deve ser analisada com cuidado devido ao fato de a técnica ser muito sensível e identificar a presença do DNA bacteriano, mesmo sem a viabilidade da bactéria; nesta circunstância, o patógeno não representaria risco para a saúde pública. Por outro lado, a detecção de $Y$. enterocolitica pelo método convencional pode subestimar sua presença, caso a bactéria se encontre injuriada, dificultando seu isolamento.

Não houve diferença entre o número de amostras positivas quando se utilizou carcaça ou tonsilas, analisadas pela técnica de PCR. Foi possível o isolamento de $Y$. enterocolitica em 22 dos 30 animais testados $(73 \%)$, considerando os dois tipos de amostras. Três animais foram positivos para carcaça e tonsila simultaneamente $(10 \%)$, nove positivos somente para as amostras de carcaças $(30 \%)$ e 10 positivos somente para as amostras de tonsilas (33\%) (Fig. 1).

Considerando que houve resultados positivos simultâneos para a presença de $Y$. enterocolitica em carcaças e tonsilas em apenas três suínos $(10 \%)$, a influência da tonsila na contaminação da carcaça não foi tão evidente nesta pesquisa, resultado já observado por Asplund (1990) e De Boer e Nouws (1991). Deduz-se que a contaminação da maioria das carcaças com $Y$. enterocolitica $(9 / 30)$ resultou de maior influência de outras fontes de contaminação, possivelmente operações de abate associadas com contaminação fecal, pessoal e ambiental. 


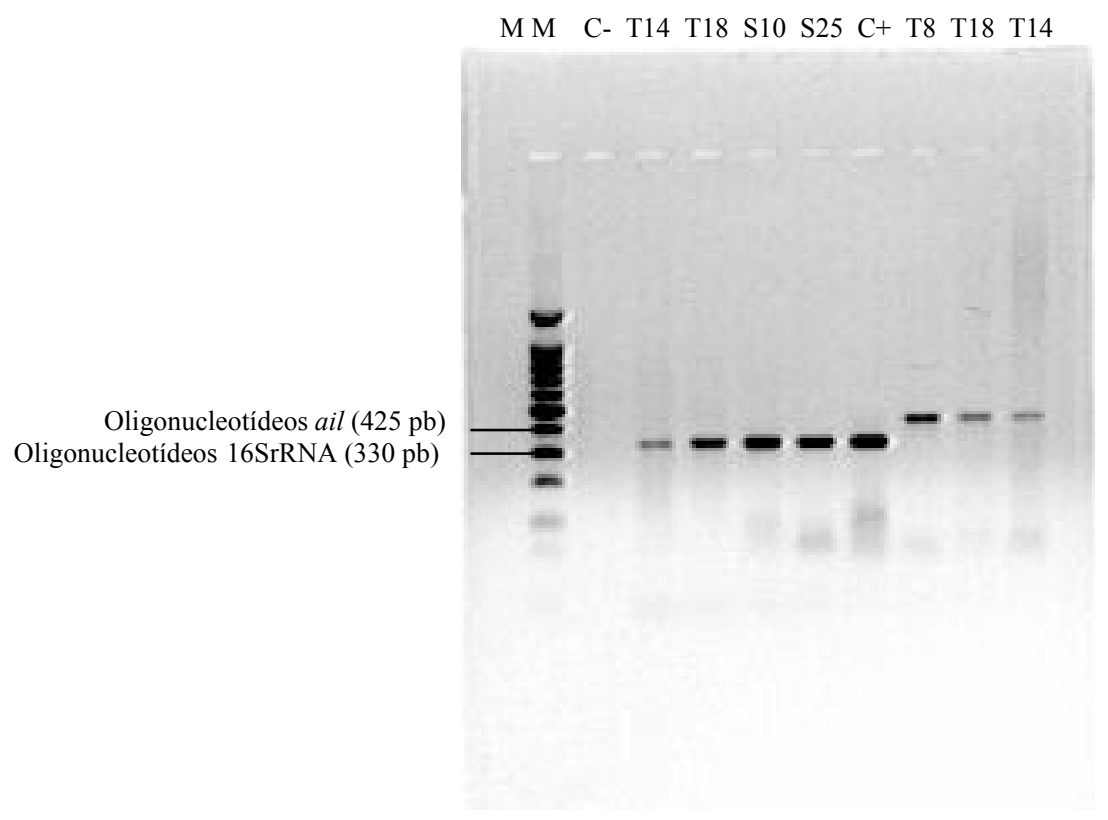

Figura 1. Resultados da PCR de amostras de tonsilas (T) e carcaças $(\mathrm{S})$ e dos controles positivo $(\mathrm{C}+)$, negativo (C-), segundo o marcador molecular Sigma øX174 (MM), evidenciando a presença de $Y$. enterocolitica (16srRNA) e Y. enterocolitica patogênica (ail).

$\mathrm{O}$ isolamento de $Y$. enterocolitica patogênica nas amostras de tonsilas $(10 \%)$ alerta para a presença de animais doentes ou portadores assintomáticos, apontando para possíveis falhas no processo produtivo animal e potencial risco de contaminação da linha de abate. Além disso, amostras de tonsilas positivas para $Y$. enterocolitica (10/30), quando as carcaças foram negativas explicam a possibilidade de contaminação restrita ao órgão, considerando os dois tipos de amostras analisadas. A freqüência elevada de positivos (33\%), não pode ser negligenciada no processo de abate, sobretudo na contaminação ambiental e que pode ser prevenida com procedimentos adequados de abate. A possibilidade de contaminação da carne suína a partir das tonsilas também foi levantada por Asplund (1990).

A opção por amostrar a carcaça ou a tonsila de suínos para a análise de $Y$. enterocolitica passa a ser influenciada pela praticidade da coleta e pelo risco de contaminação da unidade amostral, da carcaça ou do ambiente. A coleta de tonsila dispensa a interrupção da linha de abate para a realização da pesquisa, o que não ocorre quando a coleta é realizada por esfregaços de superfície da carcaça. Assim, o estabelecimento em estudo não tem seu fluxo de abate alterado durante a execução desta atividade. Segundo Borch et al. (1996), procedimentos de inspeção, particularmente da região tonsilar, constituem-se riscos para a carcaça e vísceras a partir das mãos e facas e podem limitar esse local como um ponto rotineiro de coleta. Quando se separa a cabeça da carcaça, sugere-se a coleta de tonsilas posteriormente, na seção de cabeça do estabelecimento, visando contornar esse inconveniente.

Muitos suínos abatidos estão contaminados com cepas patogênicas de $Y$. enterocolitica e, assim, a prevenção da contaminação das carcaças com fezes e tonsilas passou a ser importante medida sanitária (De Boer e Nouws, 1991).

Mais estudos são necessários para se desenvolver e aperfeiçoar as técnicas de detecção da Yersinia, bem como definir qual o melhor tipo de amostra a ser utilizada para monitoramento da $Y$. enterocolitica em situações isoladas de controle ou inseridas em plano APPCC específico. 


\section{CONCLUSÕES}

A PCR apresentou-se como uma boa alternativa na identificação de Yersinia enterocolitica, mostrando-se uma técnica aparentemente mais eficaz, rápida e econômica, que pode ser aliada à técnica microbiológica convencional em investigações de surtos e até mesmo para monitoramento da qualidade da carne suína. Considerando que não houve diferença apreciável entre os resultados positivos para $Y$. enterocolitica nas amostras de tonsilas $\mathrm{e}$ esfregaços de superfície das carcaças, a escolha de uma ou outra vai depender das condições experimentais ou do interesse da análise. A presença de $Y$. Enterocolitica patogênica nas amostras de tonsila alerta para a presença de animais doentes ou portadores assintomáticos, apontando para possíveis falhas no processo produtivo animal e potencial risco de contaminação na linha de abate.

\section{REFERÊNCIAS BIBLIOGRÁFICAS}

AARTS, H.J.M.; JOOSTEN, R.G.; HENKENS, M.H.C. et al. Rapid duplex PCR assay for the detection of pathogenic $Y$. enterocolitica strains. J. Microbiol. Meth., v.47, p.209-217, 2001.

ASPLUND, K.; TUOVINEM, V.; VEIJALAINEN, P. et al. The prevalence of Yersinia enterocolitica 0:3 in finnish pigs and pork. Acta Vet. Scand., v.31, p.39-43, 1990.

BORCH, E.; NESBAKKEN, T.; CHRISTENSEN, H. Hazard identification in swine slaughter with respect to foodborne bacteria. Int. J. Food Microbiol., v.30, p.9-25, 1996.

DE BOER, E.; NOWS, J.F.M. Slaughter pigs and pork as a source of human pathogenic Yersinia enterocolitica. Int. J. Food Microbiol., v.12, p.375-378, 1991.

DOYLE, M.P.; HUGDAHL, M.B. improved procedure for recovery of Yersinia enterocolitica from meets. Appl. Environ. Microbiol., v.45, p.127-135, 1983.

FUKUSHIMA, H.; HOSHIMA, K.; ITOGAWA, U. et al.. Introduction into Japan of pathogenic Yersinia through imported pork beef and fuwl. Int. J. Food Microbiol., v.35, p.205-212, 1997.

GERMANO, P.M.L.; GERMANO, M.I.S. Higiene $e$ vigilância sanitária de alimentos. Qualidade das matérias primas. Doenças transmitidas por alimentos: treinamento de recursos humanos. 2.ed. São Paulo: Varella, 2003. 655p.

JOHANNESSEN, G.S.; KAPPERUD, G.; KRUSE, H. Occurrence of pathogenic Yersinia enterocolitica in norwegian pork products determined by a PCR method and a traditional culturing method. Int. J. Food Microbiol., v.54, p. $75-80,2000$
LEAL, T.C.A.; LEAL, N.C.; ALMEIDA, A.M.P. Marcadores de patogenicidade em Yersinia enterocolitica 0:3 isoladas de suínos no Rio de Janeiro. Pesq. Vet. Bras., v.17, p.19-24, 1997.

NESBAKKEN, T. Enumeration of Yersinia enterocolitica $0: 3$ from the porcine oral cavity, and its occurrence on out surfaces of pig carcasses and the environement in a slaughterhouse. Int. J. Food Microbiol., v.60, p.287-293, 1988

NESBAKKEN, T.; ECKNER, K.; HOIDAL, H.K. et al. Occurrence of Yersinia enterocolitica and Campylobacter spp. in slaughter pigs and consequences for meat inspection, slaughtering, and dresssing procedures. Int. J. Food Microbiol., v.80, p.231-240, 2003.

NEUBAUER, H.; HENSEL, A.; ALEKSIC, S. et al. Evaluation of na adhesion gene of Yersinia (yadA) PCRspecific for identifications of enteropathogenic Yersinia enterocolitica. Int. J. Food Microbiol., v.57, p.225-227, 2000.

ORGANIZAÇÃO PAN-AMERICANA DE SAÚDE / INSTITUTO PAN-AMERICANO DE PROTEÇÃO DE ALIMENTOS - OPAS/INPPAZ. HACCP: Instrumento essencial para a inocuidade de alimentos. Buenos Aires, Argentina, 2001. 333p.

RAJIC, A. Does Yersinia enterocolitica from pork deserve more attention as a food safety problem? Issue of Animal Health Forum. Mar 31, 2000. Disponível em $<$ http://www.nal.usda.gov/fsrio/topics/tpy_enterocolitica.htm $>$ Acessado em jan 2004.

SAMBROOK, J.; FRITSCH, E.F.; MANIATIS, T. Molecular cloning: a laboratory manual. 2.ed. Cold Spring Harbor Laboratory, 1989. p.E-3 e E-4. 396p.

SCHIEMANN, D.A. Development of a two-step enrichment procedure for recovery of Yersinia enterocolitica from food. Appl. Environ. Microbiol., v.43, p.14-27, 1982.

SILVA, N.; JUNQUEIRA, V.C.A.; SILVEIRA, N.F.A.. Manual de métodos de análise microbiológica de alimentos. São Paulo: Varela, 1997. p.125-131

SULAKVEILIDZE, A. Yersiniae other than $Y$. enterocolitica, $Y$. pseudotuberculosis and $Y$. pestis: the ignored species. Microb. Infect., v.2, p.497-513, 2000.

UYEDA, J.; HARMON, K.; WESLEY, I. A PCR ELISA method for the detection of Yersinia enterocolitica. Disponível

$<$ http://www.extension.iastate.edu/Pages/ansci/ swuinereposts/asl-1419.pdf>. Acessado em set 2003.

WALKER, S.J.; GILMOUR, A. A comparison of media and methods for the recovery of Yersinia enterocolitica and Yersinia enterocolitica-like bacteria from milk containing simulated raw milk microfloras. J. Appl. Microbiol., v.60, p.175-183, 1986.

WANNET, W.J.B.; REESSINK, M.; BRUNINGS, H.A. et al. Detection of pathogenic Yersinia enterocolitica by a rapid duplex PCR assay. J. Clin. Microbiol., v.39, p.4483-4486, 2001 